\title{
Interleukin-8/CXCL8 Forms an Autocrine Loop in Fetal Intestinal Mucosa
}

\author{
AKHIL MAHESHWARI, ATILANO LACSON, WENGE LU, SAMUEL E. FOX, \\ AARON A. BARLEYCORN, ROBERT D. CHRISTENSEN, AND DARLENE A. CALHOUN \\ Division of Neonatology, Department of Pediatrics, University of South Florida College of Medicine, \\ Tampa, Florida, U.S.A. [A.M., W.L., S.E.F., A.A.B., R.D.C., D.A.C.], and Department of Pediatrics [A.M., \\ W.L., S.E.F., A.A.B., R.D.C., D.A.C.], Department of Pathology [A.L.], All Children's Hospital, St. \\ Petersburg, Florida, U.S.A.
}

\begin{abstract}
IL-8/CXC ligand (CXCL) 8 is ingested in high concentrations by the human fetus/neonate with amniotic fluid and human milk, and is also produced constitutively by intestinal epithelial cells (IEC). We have shown that recombinant human IL-8/CXCL8 (rhIL-8/CXCL8) protects cultured IEC against tumor necrosis factor (TNF)- $\alpha$ and cycloheximide-induced cytotoxicity. In view of its constitutive production, we hypothesized that IL-8/CXCL8 might play an autocrine role in fetal enterocyte maintenance. In this study, we measured IL-8/CXCL8 mRNA concentrations in fetal intestine (11-22 wk gestation), sought the presence of the protein by immunohistochemistry in fetal stomach and intestine (9-24 wk), measured IL-8/CXCL8 in neonatal gastric secretions, and studied constitutive and stimulated IL-8/CXCL8 expression in cultured IEC. We found that IL-8/CXCL8 is consistently transcribed and expressed in fetal intestinal tissue, in a developmentally regulated inverse relationship with gestational maturation. The cognate receptors for IL-8/CXCL8 are also expressed abundantly in the fetal intestine, and, therefore, we sought to determine whether the expressed IL-8/CXCL8 would complete an autocrine loop. Neutralization of IL-8/CXCL8 resulted in increased cell death in cultured IEC in the presence of TNF- $\alpha$.
\end{abstract}

\section{ABSTRACT}

This effect is specifically mediated through the CXCR2 receptors. We speculate that IL-8/CXCL8 secretion during cytotoxic stress reflects a cellular self-defense mechanism. (Pediatr Res 56: 240-249, 2004)
IEC, intestinal epithelial cell

\section{Abbreviations}
TNF- $\alpha$, tumor necrosis factor-alpha
CXCL, CXC ligand (the nomenclature "CXC" denotes the presence of a conserved tripeptide "cysteine-variable amino acid-cysteine" motif in the N-terminal loop of the chemokine)
CXCR, CXC receptor
IRB, institutional review board
CK18, cytokeratin 18
DAPI, 4,6-diamdino-2-phenylindole
NMP 41/7, nuclear matrix protein $41 / 7$
bZIP, transcription factors with a basic DNA-binding region and a leucine-zipper oligomerization domain
C/EBP, CCAAT/enhancer-binding protein
AP-1, activator protein-1

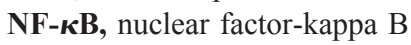

The human fetus and the neonate ingest biologically significant concentrations of IL-8/CXCL8 in amniotic fluid and human milk (1-5). We have shown recently that IL-8/CXCL8 remains intact through in vitro simulations of neonatal gastric digestion, and that it has a wide range of effects on cultured $\operatorname{IEC}(5,6)$. Several investigators have also demonstrated both constitutive and regulated IL-8/CXCL8 expression in cultured IEC and intestinal organ culture, with evidence that such secretion is dynamically influenced by other cytokines and peptide growth factors (7-11).

In this study, we studied IL-8/CXCL8 expression in the fetal/neonatal intestine by several modalities, and attempted

Received June 16, 2003; accepted February 5, 2004.

Correspondence: Akhil Maheshwari, M.D., NHB 525619 19th St. South, Birmingham, AL 35233, U.S.A.; E-mail: Akhil@peds.uab.edu

Supported by grants HD-01180 (D.A.C.), HL-61798 (R.D.C.), and HD-42326 (D.A.C.) from the National Institutes of Health.

DOI: 10.1203/01.PDR.0000133196.25949.98 to identify relationships, if any, with gestational age and IEC differentiation. We have previously shown that both the cognate receptors for IL-8/CXCL8, CXCR1 and CXCR2, are expressed in the fetal intestine as well as on several IEC lines. It is interesting that whereas $\mathrm{TNF}-\alpha$ is a potent inducer of IL-8/CXCL8 secretion in IEC (7-11), its toxicity (in combination with cycloheximide) in these cells can be limited in vitro by rhIL-8/CXCL8 (5). We hypothesized that endogenously produced IL-8/CXCL8 plays an autocrine role in the intestinal mucosa with similar cytoprotective effects, and tested it in neutralization experiments.

\section{MATERIALS AND METHODS \\ IL-8/CXCL8 Expression}

IL-8/CXCL8 mRNA concentrations in fetal intestinal tissue. IL-8/CXCL8 mRNA expression was measured in archived 
frozen fetal intestinal tissue samples (11-12 wk: $n=2 ; 13-17$ wk: $n=4 ; 18-22$ wk: $n=3$ ). Use of these tissues was approved by the local institutional review board. Total RNA was isolated and purified by using the QIAGEN mRNEasy fibrous tissue kit (QIAGEN, Valencia, CA, U.S.A.). IL-8/ CXCL8 mRNA was measured in $2 \mu \mathrm{g}$ of total RNA from each tissue sample by a sandwich ELISA technique (Quantikine colorimetric mRNA quantitation kit, R \& D Systems, Minneapolis, MN, U.S.A.). This assay is based on hybridization of specific mRNA with gene-specific biotin-labeled capture oligonucleotide probes, followed by application of digoxigeninlabeled detection probes in a microplate. The hybridization solution is then transferred to a streptavidin-coated microplate, wherein it is read with an alkaline phosphatase-based colorproducing reaction. The plates are read spectrophotometrically at $450 / 690 \mathrm{~nm}$.

IL-8/CXCL8 expression in fetal gastrointestinal tissue. IL8/CXCL8 expression was studied by immunohistochemistry in archived paraffin-embedded human fetal gastric and small intestinal tissue samples. We studied fetal duodenum at $9 \mathrm{wk}$ gestation $(n=2), 11-12$ wk gestation $(n=2), 13-17$ wk $(n=$ $4), 22-24 \mathrm{wk}(n=3)$; fetal stomach at $11-12 \mathrm{wk}(n=2)$ and $22-24$ wk $(n=2)$; and adult duodenal biopsy samples. Affinity-purified monoclonal $\mathrm{IgG}_{1}$ anti-human IL-8/CXCL8 antibody (1:80; clone $6217, \mathrm{R} \& \mathrm{D}$ Systems) was used for immunostaining in the NexES automated slide-staining system (Ventana Medical Systems, Tucson, AZ, U.S.A.), with diaminobenzidine as chromogen. Negative controls were performed by using mouse $\mathrm{IgG}_{2 \mathrm{a}}$ isotype antibody, and leukocytes on human peripheral blood smears were used as positive controls. The experiment was also repeated in a few sections using a polyclonal goat anti-human IL-8/CXCL8 antibody (which has affinity for a different epitope on the IL-8/CXCL8 molecule) and its blocking peptide (Santa Cruz Biotechnology, Santa Cruz, CA, U.S.A.) to further confirm the specificity of immunoreactivity noted in these sections.

$I L-8 / C X C L 8$ concentrations in neonatal gastric luminal contents. Gastric contents were collected from five preterm (31-34 completed weeks) and five term (37-41 wk) infants after approval by the local institutional review board. These infants were admitted in the neonatal intensive care unit, were beyond $24 \mathrm{~h}$ of age, had an indwelling oro-/nasogastric catheter, were not receiving any oral feedings, and did not have any known pulmonary/gastrointestinal inflammatory condition. The gastric secretions were stored frozen at $-80^{\circ} \mathrm{C}$, and cleared of particulate material by centrifugation at $14,000 \times g$ for 10 min before analysis. IL-8/CXCL8 was measured with a commercially available ELISA kit ( $\mathrm{R} \& \mathrm{D}$ Systems). The assay requires $50 \mu \mathrm{L}$ of sample and detects $10-3000 \mathrm{pg} / \mathrm{mL}$ of IL-8/CXCL8. Standard curves were also prepared using spiked gastric aspirate samples, besides the standards provided by the manufacturer. Test samples were run in duplicate, and the plates were read spectrophotometrically at $450 / 540 \mathrm{~nm}$.

IL-8/CXCL8 expression in intestinal epithelial cell lines. IL-8/CXCL8 expression in the intestine was further studied in vitro utilizing cultured IEC. We used two fetal intestinal cell lines (H4 cells, a gift from Prof. W. Allen Walker, Harvard University, Boston, MA, and the FHs-74-Int cells, purchased from American Type Culture Collection, Manassas, VA, U.S.A.) and compared these with Caco- 2 cells (American Type Culture Collection), which are an established model for human adult small intestinal epithelium (12). The $\mathrm{H} 4$ cell line has been developed from fetal small intestinal epithelial cells at 20-22 wk gestation (13), whereas the FHs-74-Int is derived from a 12-16 wk human fetus. The conditions for propagation of the three cell lines were as reported elsewhere (5). We used cell passage numbers $60-80$ for Caco- 2 cells, $30-35$ for $\mathrm{H} 4$ cells, and 13-15 for the FHs-74-Int cells.

Culture supernatants were harvested from three plates of each cell line at $80-100 \%$ confluence, and IL-8/CXCL8 was measured (for each supernatant sample) in duplicate by ELISA (R \& D Systems). These results were standardized for protein concentration in the cell pellets obtained after centrifugation (BCA protein assay, Pierce Biotechnologies, Rockford, IL, U.S.A.).

Cells were then plated in a 96-well plate at a density of $1 \times$ $10^{4} /$ well and studied as controls, after stimulation for $24 \mathrm{~h}$ with TNF- $\alpha(50,150,250 \mathrm{ng} / \mathrm{mL})$ (R \& D Systems) and with Escherichia coli O55:B5 lipopolysaccharide $(50 \mu \mathrm{g} / \mathrm{mL}$; Fluka Industriestrasse, Buchs SG, Switzerland). All experiments were run in triplicate. These samples were centrifuged at 2500 $\times g$ to remove cellular debris before assay. IL-8/CXCL8 was measured in duplicate for each supernatant sample by ELISA (R \& D Systems). All IL-8/CXCL8 concentrations from these experiments are expressed as picograms per milliliter of culture supernatant from 10,000 cells.

IL-8/CXCL8 secretion was also measured in polarized Caco-2 cells in basal conditions and after stimulation with TNF- $\alpha(50 \mathrm{ng} / \mathrm{mL})$. Caco-2 cells were grown to confluence using a commercially available multi-transwell insert and media system (BioCoat HTS Caco-2 assay system, BD Biosciences, San Jose, CA, U.S.A.). Media were harvested from apical and basolateral compartments after $24 \mathrm{~h}$, and IL-8/ CXCL8 concentrations measured by ELISA (R \& D Systems).

\section{Subcellular Expression of Cognate Receptors for IL-8/CXCL8 in IEC}

We have previously reported the presence of the two receptors for IL-8/CXCL8, i.e. CXCR1 and CXCR2, on IEC in fetal intestinal sections and in cultured cells (5). The subcellular expression patterns of the two individual IL-8 receptor proteins, however, have not been described. We performed immunohistochemistry on fetal intestinal tissue samples $(n=3$, 22-24 wk gestation using monoclonal anti-human CXCR1 (IL-8 RA) (Sigma Chemical Co., St. Louis, MO, U.S.A.) and CXCR2 (IL-8 RB) (R \& D Systems) in an enzyme-labeled biotin-streptavidin-DAB technique (vide supra).

\section{Effect of Neutralization of IL-8/CXCL8 on Cellular Viability/Apoptosis}

Cell viability. Cells were plated into 96-well plates at a density of 1-2 $\times 10^{4}$ cells/well, and allowed to attach for $24 \mathrm{~h}$. The media were then changed to phenol-red free media containing $25 \mu \mathrm{g} / \mathrm{mL}$ of monoclonal anti-human IL-8/CXCL8 antibody (R \& D Systems). This concentration of anti-IL-8/ 
CXCL8 antibody was chosen arbitrarily from the IL-8/CXCL8 bioactivity neutralization curves provided by the manufacturer, so as to have an excess of antibody in the culture media. The experiment was set up in duplicate (with three runs) with cells treated with $0,50,100,150,200$, and $250 \mathrm{ng} / \mathrm{mL}$ of TNF- $\alpha$. Controls were also set up with TNF- $\alpha$ in the absence of anti-IL-8/CXCL8 antibody, and medium alone. Cell viability was evaluated after $72 \mathrm{~h}$ with a commercially available XTT assay kit (Sigma Chemical Co.). The cells were incubated with the XTT reagent for $4 \mathrm{~h}$, and the wells were then read spectrophotometrically at $450 \mathrm{~nm}$.

Cell death detection: nuclear matrix protein (NMP) 41/7 ELISA. Cells were plated into 24 -well plates at a density of $5 \times 10^{4}$ cells/well, and allowed to attach for $24 \mathrm{~h}$. The experiment was set up in five subgroups, each in triplicate (with three runs): (1) controls (medium alone), (2) treated with $50 \mathrm{ng} / \mathrm{mL}$ TNF- $\alpha$, (3) with $25 \mu \mathrm{g} / \mathrm{mL}$ (excess, vide supra) monoclonal IL-8/CXCL8 antibody, (4) with both TNF- $\alpha$ and IL-8/CXCL 8 antibody, and (5) with both TNF- $\alpha$ and IL-8/CXCL8 antibody, but rescued $2 \mathrm{~h}$ later with $10 \mathrm{nM}$ rhIL-8/CXCL8. The medium was changed after $3 \mathrm{~d}$, and the experiment was terminated on day seven. NMP 41/7 concentrations were measured in culture supernatants by ELISA (Calbiochem, San Diego, CA).

Cell death detection: Cytokeratin (CK) 18 cleavage ELISA. Caco-2 and FHs-74-Int cells were plated in 24-well plates in the five subgroups as above for $3 \mathrm{~d}$, and cell death was detected by measurement of CK18 cleavage in supernatants (M30 Apoptosense ELISA, Peviva AB, Bromma, Sweden). CK18 is one of the intermediate filaments cleaved by caspases, which leads to the exposure of a neo-epitope recognized by the M30 antibody used in this assay $(14,15)$. The assay results were standardized against cell pellet protein concentrations (Pierce Biotechnologies).

Cell death detection: DNA fragment labeling. Caco-2 cells were grown to confluence in chamber slides, and the experiment was run in the aforementioned five subgroups for $3 \mathrm{~d}$. Each subgroup was run in triplicate. The slides were treated sequentially with proteinase $\mathrm{K}$ followed by a mixture of fluorescein-labeled deoxyribonucleotides and terminal deoxynucleotidyl transferase enzyme (Fluorescein-FragEL kit, Oncogene Research Products, San Diego, CA, U.S.A.). This assay is based on incorporation of fluorescein-conjugated deoxynucleotides at the free 3 '-hydroxyl groups generated at the end of DNA fragments (16). Slides were treated with $0.1 \mu \mathrm{g} / \mathrm{mL}$ DAPI before analysis under a standard fluorescein filter (465$490 \mathrm{~nm}$ ). Results were expressed as the percentage of apoptotic cells.

\section{Role of IL-8/CXCL8 Receptors in Preventing Cell Death}

The relative contribution of CXCR1 and CXCR2 receptors in preventing cell death was assessed in neutralization experiments on Caco-2 and FHs-74-Int cells. The experiment could not be extended to $\mathrm{H} 4$ cells due to limited availability of these cells. Cells were plated as above into 24-well plates and studied in two subgroups. The first subgroup was treated with $50 \mathrm{ng} / \mathrm{mL}$ TNF- $\alpha$ and $25 \mu \mathrm{g} / \mathrm{mL}$ (excess, concentration chosen as above) monoclonal anti-human CXCR1 antibody ( R \& D Systems), whereas cells in the second were treated with 50 $\mathrm{ng} / \mathrm{mL}$ TNF- $\alpha$ and $25 \mu \mathrm{g} / \mathrm{mL}$ (vide supra) monoclonal antihuman CXCR2 antibody (R \& D Systems). Controls included cells with medium alone, and with only $50 \mathrm{ng} / \mathrm{mL} \mathrm{TNF}-\alpha$. NMP 41/7 concentrations were measured in supernatants by ELISA (vide supra).

The experiment was repeated using the Cytokeratin 18 ELISA (Peviva) as above. Caco-2 and FHs-74-Int cells were plated in 24-well plates, and cell death was detected after $3 \mathrm{~d}$.

\section{Statistical Methods}

All results were rounded to last significant figure according to sensitivity of the assay used, and described as mean \pm SD. Continuous, independently measured data points were identified as parametric or nonparametric by testing for normality (Kolmogorov-Smirnov/Shapiro-Wilk tests) and equivalence of variance (Levene's test). Comparison of subgroup means was done by ANOVA (with posthoc Dunnett's $t$ test) for parametric, or the Kruskall-Wallis test for nonparametric data. For all statistical procedures, an $\alpha$-error up to 0.05 was accepted.

\section{RESULTS}

\section{IL-8/CXCL8 Expression}

IL-8/CXCL8 mRNA concentrations in fetal intestinal tissue. IL-8/CXCL8 mRNA was detected in all fetal intestinal tissue samples. Concentrations were $1775 \pm 306,1689 \pm 788$, and $2380 \pm 1413 \mathrm{fg} / \mu \mathrm{g}$ total RNA at $11-12 \mathrm{wk}, 13-17 \mathrm{wk}$, and 18-22 wk gestation, respectively, which were not statistically different from each other $(p=0.52)$ (Fig. 1).

IL-8/CXCL8 expression in fetal gastrointestinal tissue. IL8/CXCL8 immunoreactivity was observed in human fetal gastric and intestinal tissue. Staining was recorded in the crypt areas and the muscularis layer at 9 wk of gestation. At 11-18 wk, strong immunoreactivity was present in the brush border epithelium along the entire crypt-villus axis, and also in lamina propria and the muscularis layers. Staining was relatively restricted to crypt cells at $24 \mathrm{wk}$, and was very minimal in the

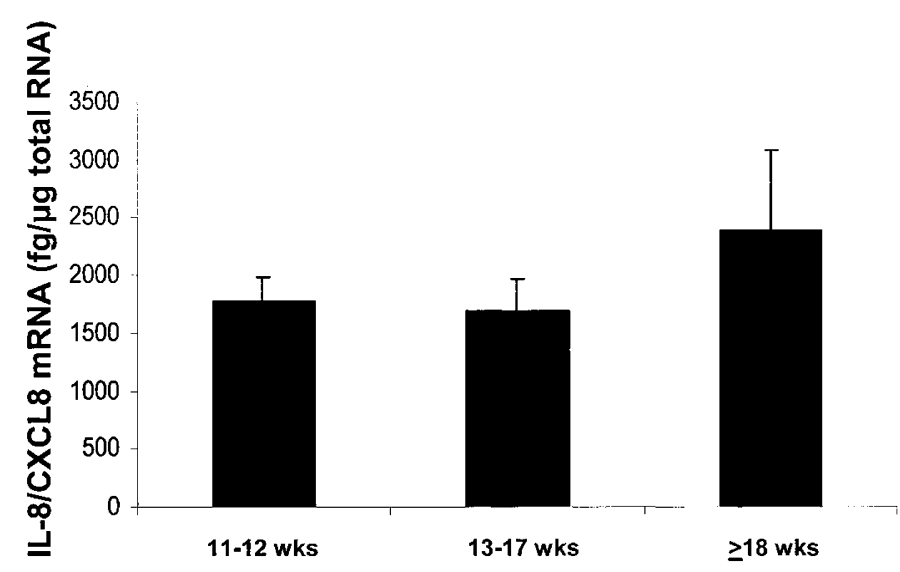

Figure 1. Bar diagram (means + SEM) showing IL-8/CXCL8 mRNA concentrations in human fetal intestine ( $\mathrm{fg} / \mu \mathrm{g}$ of total RNA). The total RNA samples were isolated from $n=2$ at $11-12 \mathrm{wk}, n=4$ at $13-17 \mathrm{wk}$, and $n=$ 3 at $18-22$ wk of gestation. 
adult duodenal biopsy sections. Similarly, strong immunoreactivity was present in the gastric mucosal epithelium at $11 \mathrm{wk}$, but could only be seen in gastric pits at $24 \mathrm{wk}$ (Fig. 2). At higher magnification, IL-8/CXCL8 immunoreactivity could be noted in IEC in both apical and basolateral patterns in the crypts, but was relatively localized to the apical areas in villus
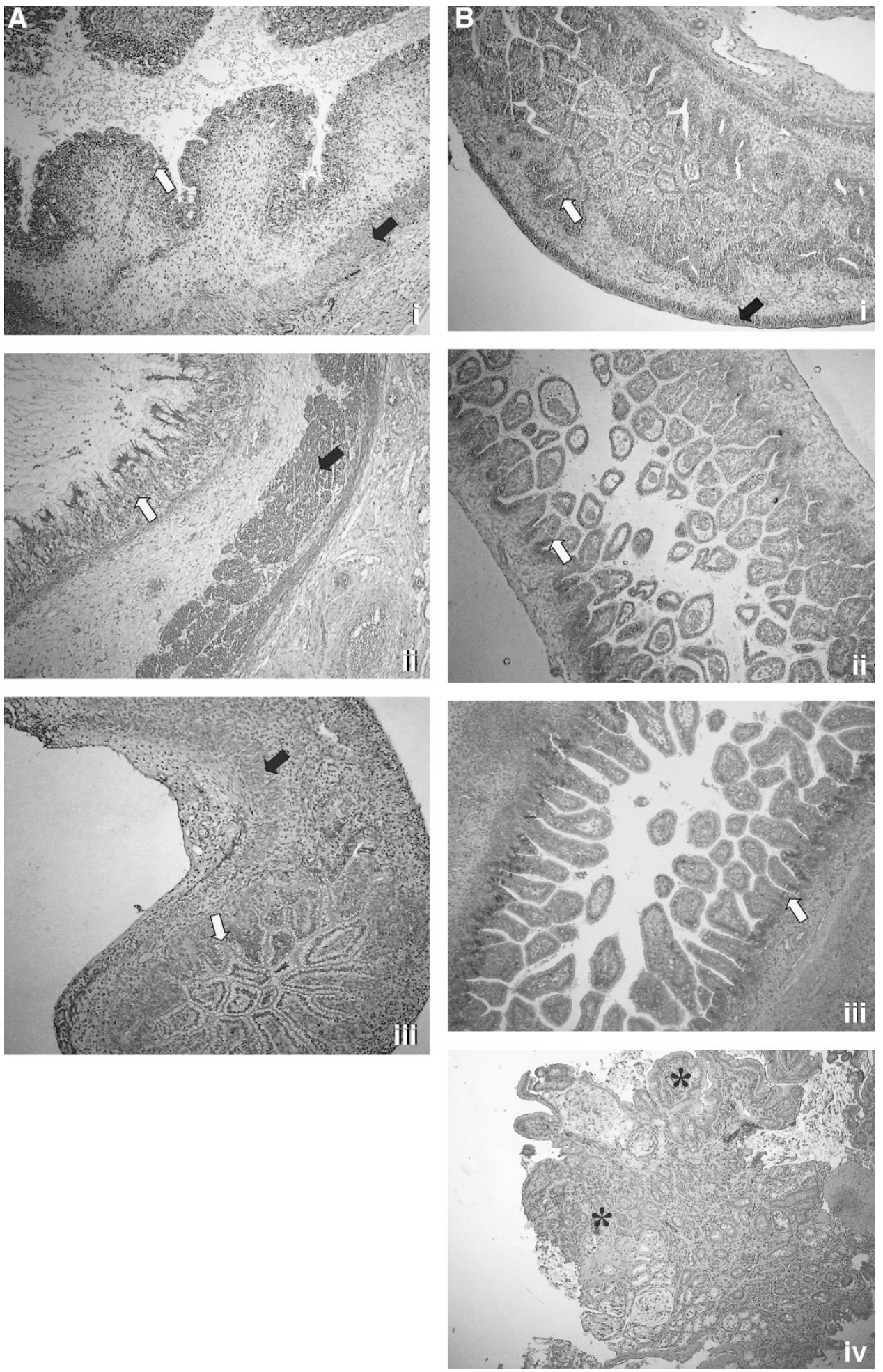

Figure 2. Immunohistochemistry for IL-8/CXCL8 in fetal gastric and duodenal sections. Representative sections $(100 \times)$ of $(A)$ human fetal stomach at $(i) 11$ wk gestation, showing strong immunoreactivity in the epithelial cell (white arrow) and muscularis layers (black arrow); (ii) 24 wk gestation, with diminished immunoreactivity in epithelial cells, which is more limited to the gastric pits. (B) Human fetal duodenum at (i) 9 wk gestation showing immunoreactivity in intervillus (crypt) epithelial cells (white arrow) and the muscular layer (black arrow); (ii) 11 wk gestation with slightly stronger immunoreactivity in epithelial and muscular layers; (iii) $16 \mathrm{wk}$ gestation with persistent and easily discernible immunoreactivity; (iv) $24 \mathrm{wk}$ gestation with immunoreactivity relatively limited to the crypts; $(v)$ human adult duodenal biopsy, showing absence of immunoreactivity in epithelial cells. The blood vessel walls show positive staining (asterisk). An enzyme-labeled biotin-streptavidin technique was used with diaminobenzidine tetrahydrochloride as the chromogen (brown). 

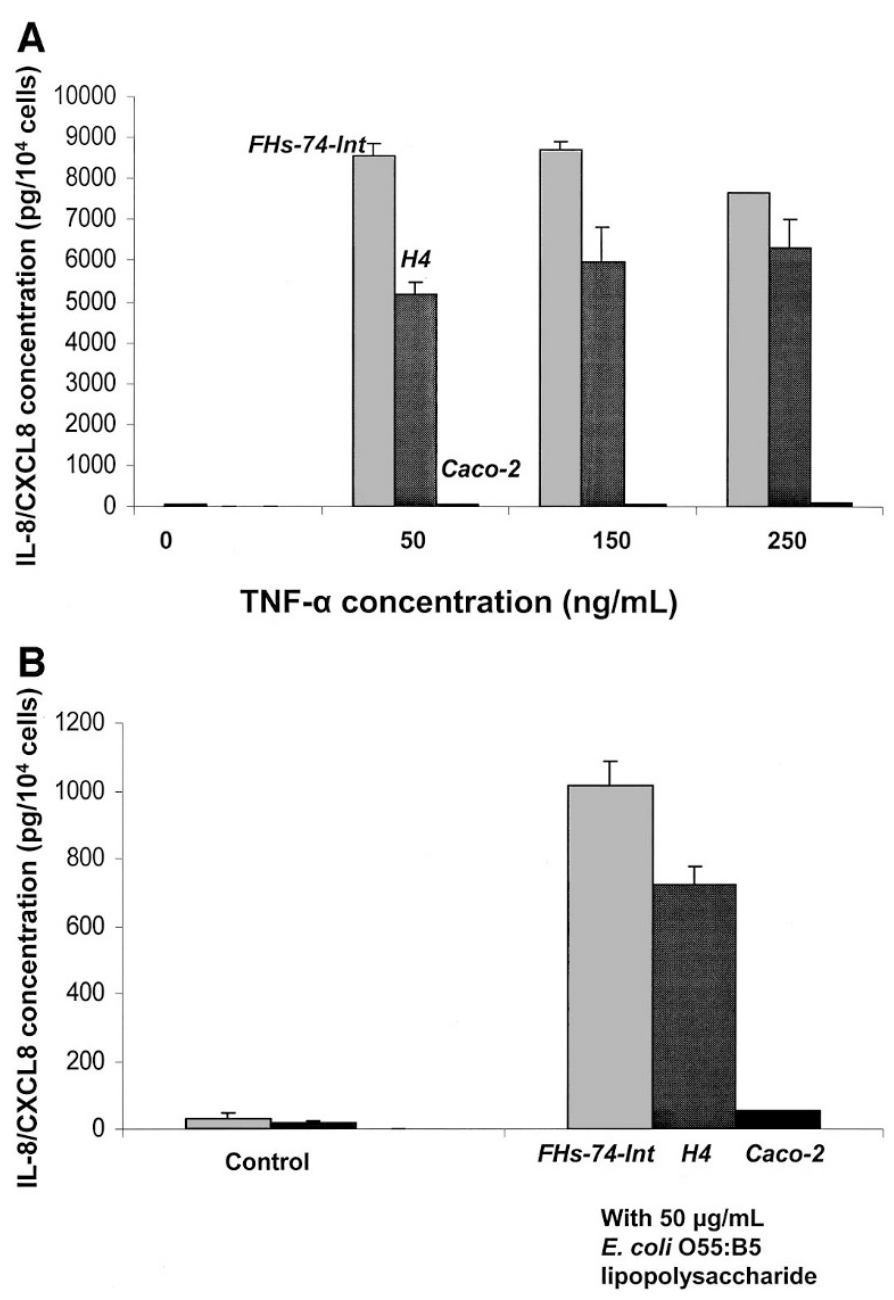

Figure 3. Bar diagrams (means + SEM) showing IL-8/CXCL8 concentrations in supernatants from cultured IEC after stimulation with $(A)$ TNF- $\alpha$ or (B) LPS. All experiments were run in triplicate.

tips (Fig. 4). The immunostaining pattern with the polyclonal goat anti-human IL-8/CXCL8 was markedly similar, and was completely inhibited by its blocking peptide.

IL-8/CXCL8 concentrations in neonatal gastric luminal contents. IL-8/CXCL8 was measurable in gastric contents, and was significantly higher in preterm $(2569 \pm 581 \mathrm{pg} / \mathrm{mL})$ than term $(1022 \pm 297 \mathrm{pg} / \mathrm{mL})$ neonates $(p=0.001)$.

IL-8/CXCL8 expression in intestinal epithelial cell lines. IL-8/CXCL8 was detectable in culture supernatants from all the three cell lines. The concentrations were $159 \pm 15,27 \pm$ 9, and $6 \pm 2 \mathrm{pg} / \mathrm{mg}$ protein in FHs-74-Int, H4, and Caco-2 cells, respectively $(p<0.001)$.

When stimulated with TNF- $\alpha$, IL-8/CXCL8 production increased significantly in all three cell lines. The unit of measurement in this assay was $\mathrm{pg} / \mathrm{mL}$ of supernatant (for $10^{4}$ cells). In FHs-74-Int cells, IL-8/CXCL8 concentrations increased from control $32 \pm 17 \mathrm{pg} / \mathrm{mL}$ to $8551 \pm 424,8703 \pm$ 288 , and $7645 \pm 50 \mathrm{pg} / \mathrm{mL}$ with $50,150,250 \mathrm{ng} / \mathrm{mL}$ of TNF- $\alpha$ (all $p<0.001$ compared with control). The concentrations in $\mathrm{H} 4$ cells increased from $17 \pm 6$ to $5190 \pm 368,5961 \pm 1217$, and $6327 \pm 950 \mathrm{pg} / \mathrm{mL}(p=0.003,0.002,0.002$, respectively) whereas in Caco-2 cells IL-8/CXCL8 concentrations increased from below detectable limit in controls to $70 \pm 3,60 \pm 6,79$ $\pm 3 \mathrm{pg} / \mathrm{mL}$ (all $p<0.001$ ). The stimulated production was higher in FHs-74-Int than $\mathrm{H} 4$ cells, which in turn was higher than Caco- 2 cell line (all $p<0.01$ compared with control). In the individual cell lines, the expression of IL-8/CXCL8 did not differ between the incremental concentrations of TNF- $\alpha$ ( $p=$ $0.34-0.98$ ). These results have been depicted in Figure 3.

IL-8/CXCL8 concentrations also increased significantly in all three cell lines after stimulation with LPS. In FHs-74-Int cells, the concentrations increased from $32 \pm 24 \mathrm{pg} / \mathrm{mL}$ in controls to $1015 \pm 100 \mathrm{pg} / \mathrm{mL}$ with LPS ( $p=0.005$ ). In H4 cells, the levels rose from $16 \pm 6$ to $724 \pm 72 \mathrm{pg} / \mathrm{mL}(p=$ 0.005), whereas in Caco-2 cells IL-8/CXCL8 concentrations increased from below detectable limit to $52 \pm 4 \mathrm{pg} / \mathrm{mL}$ ( $p=$ 0.002). Stimulated IL-8/CXCL8 expression differed significantly between the three cell lines $(p<0.05)$.

IL-8/CXCL8 expression in polarized Caco-2 monolayers was predominantly basolateral. The concentration increased from below detectable limits in basal conditions to $18 \pm 7$ $\mathrm{pg} / \mathrm{mL}$ in apical and $32 \pm 4 \mathrm{pg} / \mathrm{mL}$ in basolateral compartments following stimulation with TNF- $\alpha(p=0.04)$.

\section{Subcellular Expression of Cognate Receptors for IL-8/CXCL8 in IEC}

Both CXCR1 and CXCR2 are expressed predominantly along the basolateral aspect of IEC in the crypts/intervillus areas. There is little, if any, expression along the apical surface of these cells. However, the distribution of both receptors gradually becomes more apical in IEC from the mid-villus region toward the villus tip, and the basolateral staining is progressively diminished (Fig. 4).

\section{Effect of Neutralization of IL-8/CXCL8 on Cellular Viability/Apoptosis}

Cell viability. There was no effect of TNF- $\alpha$ (50-250 ng/ $\mathrm{mL}$ ) or anti-IL-8/CXCL8 antibody alone on cell viability in any of the three cell lines $(p=0.43-0.92)$. However, in the presence of anti-IL-8/CXCL8 antibody, cell viability decreased progressively in $\mathrm{H} 4$ and $\mathrm{FHs}$-74-Int cells with increasing TNF- $\alpha$ concentrations. Significantly lower OD readings were observed with 200 and $250 \mathrm{ng} / \mathrm{mL}$ TNF- $\alpha$ in H4 cells ( $p=$ 0.037 and 0.013 , respectively), and with $250 \mathrm{ng} / \mathrm{mL}$ TNF- $\alpha$ in FHs-74-Int cells $(p=0.026)$. Such changes were, however, not observed with Caco-2 cells ( $p=0.87-0.96)$.

Cell death (NMP 41/7 ELISA). NMP 41/7 concentrations were similar in supernatants from controls, from cells treated with TNF- $\alpha$, and from the cells treated with monoclonal anti-IL-8/CXCL8 antibody. When treated with both TNF- $\alpha$ and anti-IL-8/CXCL8 antibody together, NMP 41/7 concentrations increased significantly in all the three cell lines ( $p=$ 0.007, 0.036, and 0.035 for Caco-2, H4, and FHs74-Int cells). This effect was successfully reversed by the addition of $10 \mathrm{nM}$ IL-8/CXCL8 $2 \mathrm{~h}$ after treatment with TNF- $\alpha+$ anti-IL-8/ CXCL8 antibody (Fig. 5).

Cell death (CK18 ELISA). In Caco-2 cells, CK18 concentrations did not differ between controls, from cells with TNF- $\alpha$, and with anti-IL-8/CXCL8 antibody alone (546 $\pm 32,623 \pm 25$, and 

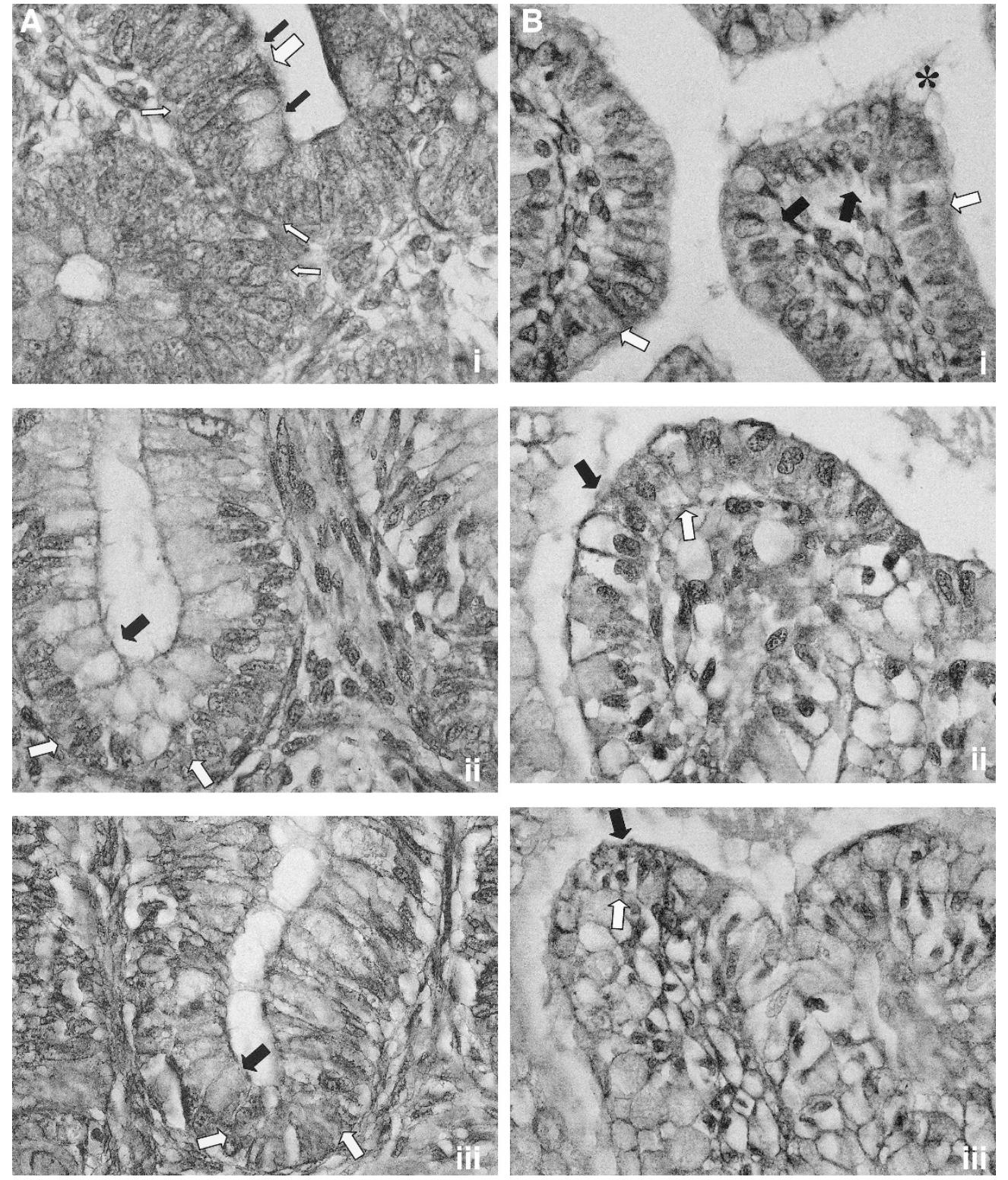

Figure 4. Higher magnification $(1000 \times)$ sections of 24 -wk fetal intestine. $(A)$ Crypt. (i) Subcellular expression of IL-8/CXCL8. There is a both basolateral (small white arrows) and apical (large white arrow) immunoreactivity. The apical staining is unlikely to be artifactual as the staining depends on cell type, and there are discontinuous areas (small black arrows). (ii) Subcellular expression of CXCR1. Basolateral (white arrow) and nuclear immunoreactivity can be noted. The apical immunoreactivity is minimal (black arrow). (iii) Subcellular expression of CXCR2. Basolateral (white arrow) immunoreactivity can be noted. The nuclei are spared. The apical immunoreactivity is minimal (black arrow). (B) Villus. (i) Subcellular expression of IL-8/CXCL8. Immunoreactivity can be noted in intestinal luminal contents (asterisk). In IEC, the immunoreactivity is predominantly apical (white arrows), and basolateral staining is minimal (black arrow). (ii) Subcellular expression of CXCR1. Apical (black arrow) and nuclear immunoreactivity can be noted. The basolateral immunoreactivity is minimal (white arrow). (iii) Subcellular expression of CXCR2. Apical (black arrow) immunoreactivity can be noted. The basolateral immunoreactivity is minimal (white arrow). An enzyme-labeled biotin-streptavidin technique was used with diaminobenzidine tetrahydrochloride as the chromogen (brown).

$567 \pm 31 \mathrm{U} / \mathrm{mg}$, respectively, $p=0.13$ ), but increased significantly in the presence of both TNF- $\alpha$ and anti-IL-8/CXCL8 antibody $(963 \pm 16 \mathrm{U} / \mathrm{mg}, p<0.001)$. These cells were successfully rescued with rhIL-8/CXCL8 in $2 \mathrm{~h}(688 \pm 109 \mathrm{U} / \mathrm{mg} ; p=$ 0.10 compared with control, but $p<0.01$ in comparison with the combined TNF- $\alpha+$ antibody subgroup). The results were similar in FHs-74-Int cells, with similar CK18 concentrations in controls, TNF- $\alpha$, and anti-IL-8/CXCL8 antibody subgroups (412 \pm 52 , $483 \pm 89$, and $465 \pm 177 \mathrm{U} / \mathrm{mg}$, respectively, $p=0.51$ ), but increased significantly in the presence of both TNF- $\alpha$ and antiIL-8/CXCL8 antibody $(1036 \pm 286 \mathrm{U} / \mathrm{mg}, p<0.01)$. These cells were also successfully rescued with rhIL-8/CXCL8 in $2 \mathrm{~h}(788 \pm$ $297 \mathrm{U} / \mathrm{mg} ; p=0.12$ compared with control, but $p<0.01$ in comparison with the combined TNF- $\alpha+$ antibody subgroup).

DNA fragment labeling. The number of apoptotic cells was similar in controls, with TNF- $\alpha$, and with anti-IL-8/CXCL8 antibody $(6 \pm 5,8 \pm 3,11 \pm 3 \%$, respectively, $p=0.26)$, increased significantly with both TNF- $\alpha$ and anti-IL-8/CXCL8 antibody $(28 \pm 11 \%, p=0.013)$, and decreased partially with rescue rhIL-8/CXCL8 $(15 \pm 6 \%, p=0.12$ compared with control, but $p<0.01$ in comparison with the combined TNF- $\alpha$ + antibody subgroup). 

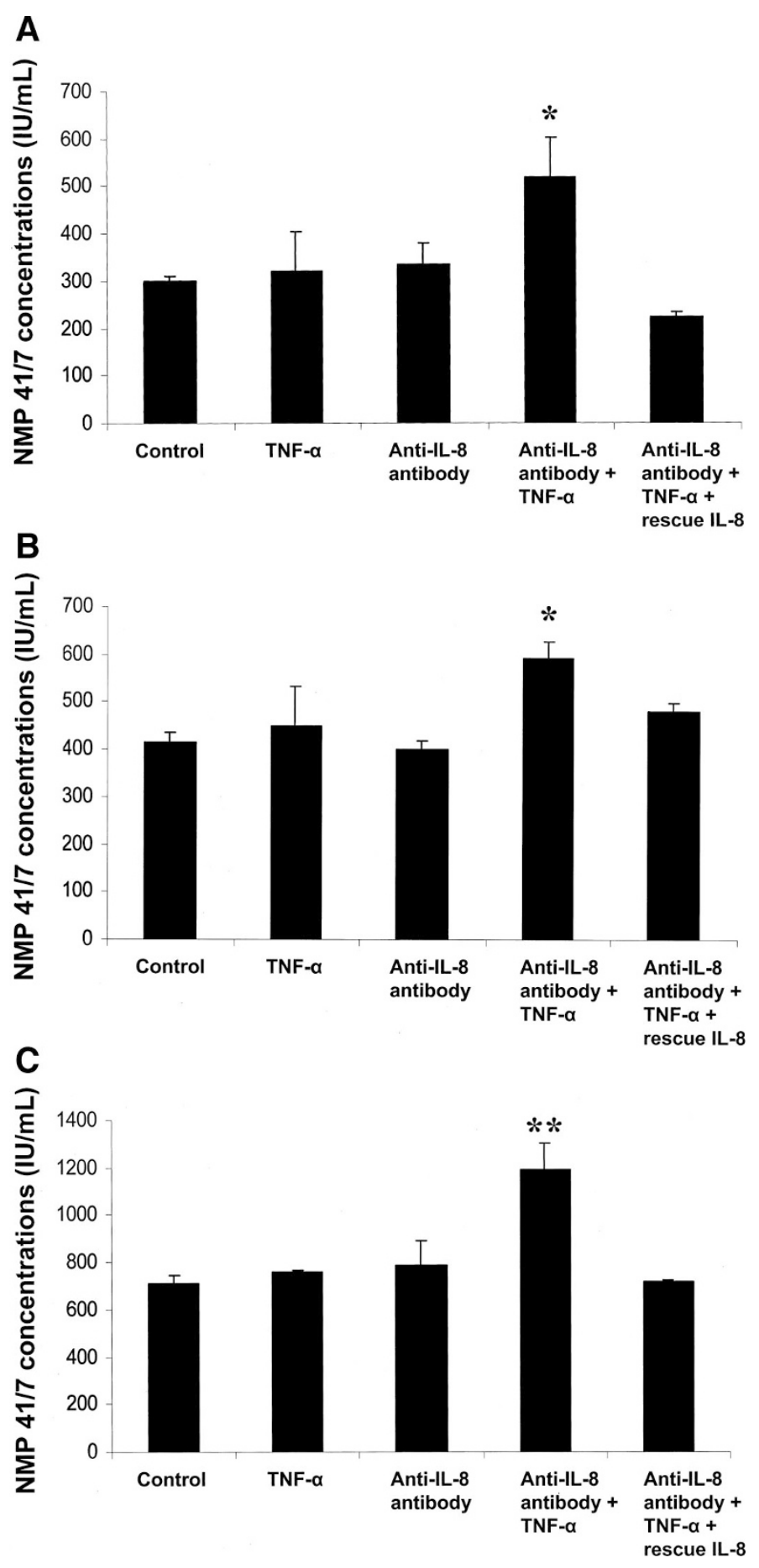

Figure 5. Bar diagram (means + SEM) showing the effect of neutralization of IL-8/CXCL8 with specific MAb in the presence of TNF- $\alpha$ on cell death (NMP 41/7) in cultured IEC. The figure shows results in $(A)$ FHs-74-Int cells (12-16 wk fetus), (B) H4 cells (20-22 wk fetus), and (C) Caco-2 cells. All five subgroups were studied in triplicate, with a total of three runs of the experiment $\left({ }^{*} p<0.05, * * p<0.01\right)$.

\section{Role of IL-8/CXCL8 Receptors in Preventing Cell Death}

In both FHs-74-Int and Caco-2 cells, NMP 41/7 concentrations were similar in controls, cells treated with TNF- $\alpha$ alone, with anti-CXCR1antibody, with anti-CXCR2 antibody, and in cells treated with TNF- $\alpha+$ anti-CXCR1 antibody. However, the concentrations increased significantly in both cell lines when treated with TNF- $\alpha+$ anti-CXCR2 antibody $(p=0.011$ for Caco-2, $p=0.001$ for FHs-74-Int cells) (Fig. 6).

The CK18 concentrations were similar in controls, cells treated with TNF- $\alpha$, anti-CXCR1 antibody, anti-CXCR2 antibody, and in cells treated with TNF- $\alpha+$ anti-CXCR1 antibody (Caco-2: $562 \pm 34,589 \pm 63,643 \pm 78,486 \pm 101,499 \pm$ $132 \mathrm{U} / \mathrm{mg}$ protein, respectively, $p=0.24$; FHs-74-Int: $423 \pm$ $78,532 \pm 67,489 \pm 34,512 \pm 94,469 \pm 54 \mathrm{U} / \mathrm{mg}$, respectively, $p=0.39$ ). The concentrations were higher in both cell lines in the presence of TNF- $\alpha+$ anti-CXCR2 antibody (Caco-2: $826 \pm 186 \mathrm{U} / \mathrm{mg}, p=0.02$; FHS-74-Int: $789 \pm 245$ $\mathrm{U} / \mathrm{mg}, p=0.03)$.

\section{DISCUSSION}

Our findings show that IL-8/CXCL8 is transcribed and expressed in the fetal intestine, and suggest that this process is developmentally regulated. IL-8/CXCL8 immunoreactivity in the epithelium was most extensive at 11-18 wk gestation along the entire crypt-villus axis, was relatively restricted to the crypt areas at 22-24 wk, and only minimally detectable in the adult duodenal biopsy sections. The expression patterns of the cells lines provide supportive evidence for this developmental regulation, as the FHs-74-Int cells (derived from a 12- to 16 -wk fetus) produced more IL-8/CXCL8 than $\mathrm{H} 4$ cells (derived from the 20- to 22-wk stage).

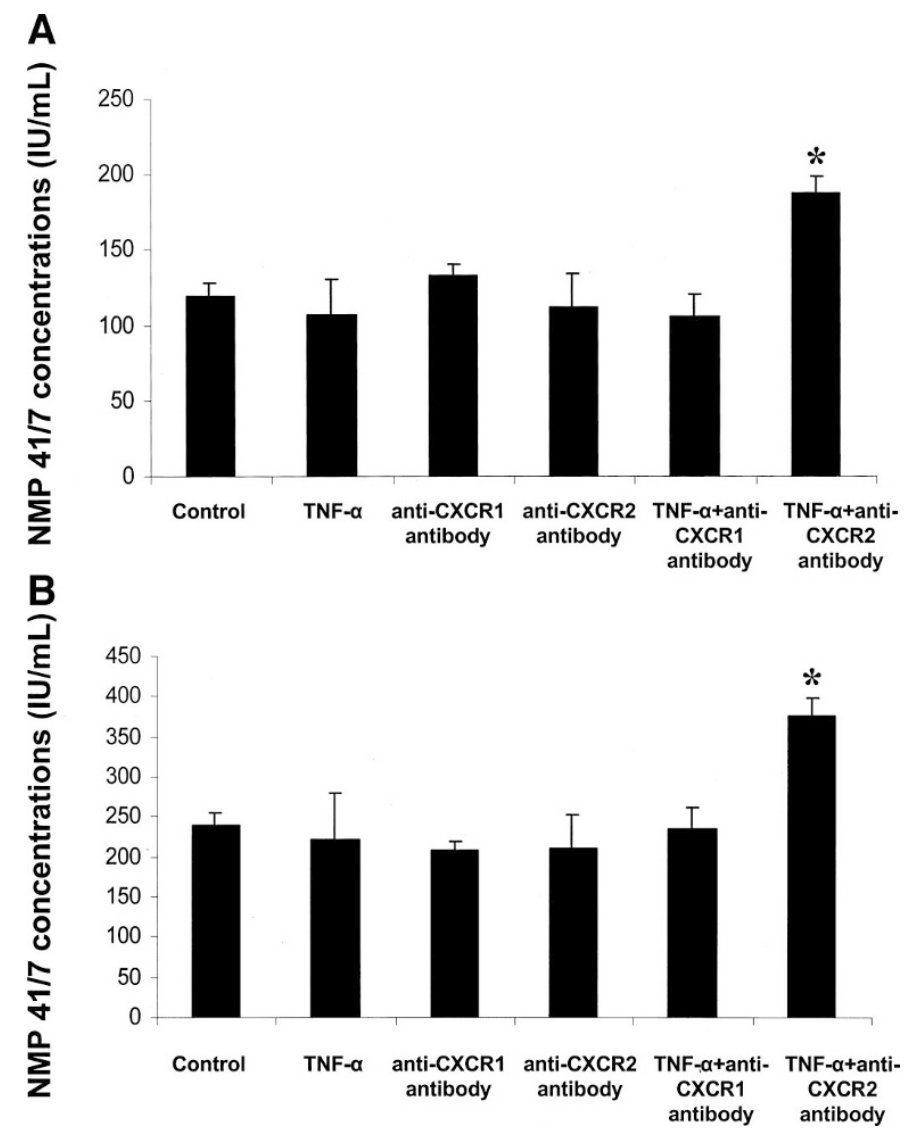

Figure 6. Bar diagram (means + SEM) showing the effect of blocking CXCR1 and CXCR2 receptors with specific MAb in the presence of TNF- $\alpha$ on cell death (NMP 41/7) in cultured IEC. The figure shows results in $(A)$ FHs-74-Int cells (12-16 wk fetus) and $(B)$ Caco-2 cells. All subgroups were studied in triplicate, in two runs $\left(* p<0.05,{ }^{*} p<0.01\right)$. 
Further confirmation of this trend in IL-8/CXCL8 expression in the developing gastrointestinal intestinal mucosa was sought by assaying neonatal gastric contents. These aspirates were collected after $24 \mathrm{~h}$ to minimize any amniotic fluid persisting from birth, but some degree of a physiologic admixture with bronchial secretions was expected. These observations, therefore, can only be seen as corroboratory evidence, even though other measurements on gastric contents such as cellularity or bacterial content correlate poorly with tracheal aspirates beyond the first day of life (17). Chemokine expression is also observed in the bronchial epithelial cells (18), and a similar negative trend of IL-8/CXCL8 concentrations with gestational maturation has been reported in bronchoalveolar lavage samples in the absence of infection (19). These findings are of interest in view of the common embryonic origin of both gastrointestinal and bronchial epithelia from the gut endoderm, and marked similarities in their individual pathways of epithelial differentiation $(20,21)$. Finally, as IL-8/CXCL8 is highly resistant to aspartyl proteinases (6), it is unlikely that the lower gastric fluid IL-8/CXCL8 concentrations in term infants could be explained based solely on increased gastric proteolytic activity.

Our findings are similar to the observations of Nanthakumar et al. (8), who reported an inverse relationship between IL-8/ CXCL8 expression and intestinal maturation. In their study, IL-8/CXCL8 mRNA/protein expression in H4 IEC and intestinal organ cultures from 18- to 21 -wk fetal intestine greatly exceeded those from infants or older children. The development of regulatory pathways involved in IL-8/CXCL8 transcription, however, remains to be studied. IL-8/CXCL8 transcription involves the interaction of constitutively expressed transcription factors of the bZIP family, such as C/EBP and $\mathrm{AP}-1$, and the immune-activated factors of the NF- $\kappa \mathrm{B} / \mathrm{rel}$ family with the promotor site (22). Recent observations on the tight developmental regulation of AP-1 genes could possibly provide further insights into these patterns (23).

In our small number of fetal intestinal tissue samples, we did not detect any difference in IL-8/CXCL8 mRNA concentrations at different gestational ages. However, besides a beta statistical error, other possibilities also merit consideration. In tissue sections, strong immunoreactivity is also notable in the muscularis layer, which would form a relatively larger RNA pool. It is, therefore, possible that changes in the brush border epithelial monolayer, due to the smaller cell number, are not reflected in the total intestinal IL-8/CXCL8 mRNA. Similarly, these findings could be explained on the basis of posttranscriptional regulation, a phenomenon well described for CXC chemokines (24). Presence of measurable IL-8/CXCL8 mRNA concentrations, in conjunction with the observations of epithelial IL-8/CXCL8 immunoreactivity in isolated intestinal organ culture from Nanthakumar et al. (8), further confirms that immunoreactivity in fetal intestinal mucosa reflects a physiologic presence and is not solely an artifact of passive adsorption from amniotic fluid.

The subcellular expression of IL-8/CXCL8 in IEC changes along the crypt-villus axis. It is interesting that while the expression is both basolateral and apical in crypt cells, it becomes predominantly apical as cells differentiate and mi- grate toward the villus tip (25). Basolateral expression of proteins has been clearly equated with secretion in IEC, whereas apical expression can be associated with both passive uptake/adsorption as well as secretion $(26,27)$. Our observation of a dual staining pattern in the crypt cells is consistent with the hypothesis that IL-8/CXCL8 is actively secreted in this region. Direct measurements from polarized Caco-2 monolayers also show a similar dual secretory pattern with basolateral predominance. The expression of IL-8/CXCL8 receptors provides further indirect evidence for this phenomenon, as both CXCR1 and CXCR2 are also expressed predominantly on the basolateral aspect of these cells, which is the same as the site of secretion of their ligand. These findings are consistent with an autocrine role of IL-8/CXCL8 in these cells.

In mid-villus and villus tip cells, the basolateral immunoreactivity is progressively lost, which is consistent with in vitro evidence that differentiation leads to diminution in IL-8/ CXCL8 production in IEC $(28,29)$. It is likely that apical staining in this region is secondary to uptake/adsorption from the luminal contents of the intestine (Fig. 4B(i)). Notably, as these cells migrate toward the villus tip, the receptor expression also becomes progressively more apical, with simultaneous loss of basolateral staining. This reversal of receptor expression would allow the uptake of IL-8/CXCL8 from the intestinal contents in the villus tip region.

In vitro, rhIL-8/CXCL8 has a wide range of effects on cultured IEC $(5,30,31)$. With evidence of autogenous secretion of IL-8/CXCL8, and the presence of its cognate receptors, we sought to confirm whether IL-8/CXCL8 completes an autocrine loop, as is known for some other cytokines such as the members of the epidermal growth factor cytokine subfamily (32). In a previous publication, we reported that rhIL-8/ CXCL8 protects IEC against chemical injury with TNF- $\alpha+$ cycloheximide (5). Hence, it was relevant to note the marked induction of autogenous IL-8/CXCL8 production in both the fetal IEC lines after TNF- $\alpha$ treatment. TNF- $\alpha$ recruits several apoptotic signal transduction pathways $(33,34)$, but is unable to induce apoptosis in IEC by itself (35). This lack of effect might be due to simultaneous transmission of anti-apoptotic signals through the NF- $\kappa \mathrm{B}$ and the phosphatidylinositol-3kinase/Akt pathways (36). As NF- $\kappa \mathrm{B}$ is the primary transcriptional activator of inducible IL-8/CXCL8 production in IEC $(22,37)$, we speculate that the anti-apoptotic effect of NF- $\kappa \mathrm{B}$ pathway against TNF- $\alpha$ is mediated through IL-8/CXCL8 expression.

Confirmation of this effect was noted by IL-8/CXCL8 neutralization in assays for measuring cellular viability and death in vitro. The smaller effect size in cell viability is likely due to replacement of dying cells by ongoing proliferation, which would also explain the absence of any effect in Caco-2 cells, a malignant cell line with higher turnover rates. The results of NMP 41/7, CK18, and DNA fragment labeling assays provide confirmation of the anti-apoptotic role of IL-8/CXCL8. NMP $41 / 7$ is cleaved and solubilized during the process of cell death, especially apoptosis (38), and its concentration in cell culture supernatants shows a high degree of correlation with cell DNA fragmentation and Fas-ligand production (39). CK18 has been similarly established to reflect cell death in epithelial cells (14, 
$15,40)$. DNA fragment labeling has been used extensively in Caco-2 cells to study apoptosis $(41,42)$, wherein its higher sensitivity and specificity, shorter preparation time, and the ability to visually discern cells undergoing apoptosis add to its value (16). Measurement of multiple parameters indicative of cell death is highly desirable in these studies as TNF- $\alpha$ induced cell death in IEC is somewhat atypical in morphology, with features that could be considered as intermediate between necrosis and apoptosis (34).

The significance of IL-8/CXCL8 expression and its induction during specific situations in the fetal intestine needs further study. TNF- $\alpha$, widely expressed in embryonic tissues, might play a role in cell death that accompanies normal morphogenesis and organogenesis (43). IL-8/CXCL8 could counterbalance this pro-apoptotic activity, which could explain developmental regulation of its expression. It is believed that decreased apoptosis, and not cell proliferation, is the primary contributor to the exponential increase in cell numbers needed for expansion of the intestinal mucosal surface area. During fetal development, IEC apoptosis is at a minimum between 9 and $17 \mathrm{wk}$ of gestation, the period of crypt-villus organization, whereas mitotic figures tend to become limited to the intervillus epithelium or crypt areas beyond $10-12$ wk $(21,44)$. Our findings that IEC IL-8/CXCL8 expression is most extensive during a similar period are, therefore, of direct interest, and merit further study by a genetic interventional approach in an animal model.

Although IL-8/CXCL8 expression is regulated with IEC differentiation, and decreases progressively from the crypts toward the villus tip, the expression of TNF- $\alpha$ in IEC does not change with differentiation (28). The gradation in IL-8/ CXCL8, an anti-apoptotic factor, against a constant background of TNF- $\alpha$, a pro-apoptotic stimulus, could theoretically explain the crypt-villus balance where the crypt cells are tilted toward proliferation and survival, whereas the villus tip cells are prone to apoptosis. In the fetus and the newborn infant, the need to increase cell mass as part of growth would favor measures to prevent the natural cellular loss at the villus tip. Such a need could explain the rationale for an exogenous source of IL-8/CXCL8 (e.g. from ingested amniotic fluid or milk) in the developing intestine, even though fetal cells are capable of significant autogenous production of IL-8/CXCL8.

The anti-apoptotic role of IL-8/CXCL8 has been investigated in several other cell types. Osawa et al. (45) recently showed a 14-fold increase in IL-8/CXCL8 gene expression after TNF- $\alpha$ stimulation in hepatocytes, and that addition of recombinant IL-8/CXCL8 abolished TNF- $\alpha$-induced apoptosis in these cells. There is also supportive evidence that this anti-apoptotic effect may be mediated primarily through interaction with the CXCR2 receptors. Glynn et al. (46) have shown that selective CXCR2 antagonist SB272844 blocks IL-8/ CXCL8-mediated inhibition of spontaneous neutrophil apoptosis. In astrocytes, IL-8/CXCL8 secretion and CXCR2 expression are both induced after Fas stimulation, and the survival of cultured astrocytes after Fas triggering is governed by IL-8/ CXCL8-CXCR2 binding (47).

It is possible that the cytoprotectant effects of IL-8/CXCL8 might be more extensive, and extend beyond TNF- $\alpha$-induced injury. In our experiments, IEC IL-8/CXCL8 expression increased after exposure to LPS. Nanthakumar et al. (8) have reported similar results with endotoxin and IL-1 $\beta$. IL-8/ CXCL8 secretion could reflect a more generalized cellular self-defense mechanism during cytotoxic stress. IEC IL-8/ CXCL8 secretion is influenced by various nutritional and local enteral factors (11), which are difficult to replicate in vitro. On the other hand, in animal models, it is difficult to separate the direct effects of IL-8/CXCL8 on epithelial cells versus those on neutrophil recruitment. Further studies need to examine a combination of models to fully investigate the cytoprotectant role of IL-8/CXCL8 in IEC.

Our experiments on the role of the individual receptors show that the anti-apoptotic role of IL-8/CXCL8 is mediated through CXCR2. Among the CXC chemokines containing the $\mathrm{N}$ terminal glutamate-leucine-arginine motif, all seven function as CXCR2 ligands, as against only IL-8/CXCL8 and granulocyte chemotactic peptide-2/CXCL6 that act on both CXCR1 and CXCR2 $(48,49)$. We have shown recently that all the seven CXCR2 ligands are present in human colostrum and milk (50). An anti-apoptotic effect of growth-related oncoprotein- $\alpha /$ CXCL1 has been observed in neutrophils (46). If the other chemokines in this subfamily indeed have a similar effect, this natural redundancy of CXCR2 ligands might be of teleologic advantage in intestinal development.

Acknowledgments. The authors thank Dr. W. Allen Walker, Harvard University, for providing us with the $\mathrm{H} 4$ cell line. We also thank Drs. Kersti Linask, Y. Clare Zhang and Nagwa Dajani, and Leping Shen, Shayam Manisastry, Mingda Han, and Jo Pascuel for providing help and education for various laboratory techniques; Dr. Ritu Shah for her help with the experiments and the manuscript; Drs. Freddy Alvarez and Avital Leibovici for thoughtful discussions; nurses Dawn Bruton, Sue Stripling, and Debbie Patrick for their help with sample and data collection; and Ingrid Williams for managerial support.

\section{REFERENCES}

1. Denison FC, Riley SC, Wathen NC, Chard T, Calder AA, Kelly RW 1998 Differential concentrations of monocyte chemotactic protein-1 and interleukin- 8 within the fluid compartments present during the first trimester of pregnancy. Hum Reprod 13:22922295

2. Laham N, Rice GE, Bishop GJ, Ransome C, Brennecke SP 1993 Interleukin 8 concentrations in amniotic fluid and peripheral venous plasma during human pregnancy and parturition. Acta Endocrinol (Copenh) 129:220-224

3. Srivastava MD, Srivastava A, Brouhard B, Saneto R, Groh-Wargo S, Kubit J 1996 Cytokines in human milk. Res Commun Mol Pathol Pharmacol 93:263-287

4. Michie CA, Tantscher E, Schall T, Rot A 1998 Physiological secretion of chemokines in human breast milk. Eur Cytokine Netw 9:123-129

5. Maheshwari A, Lu W, Lacson A, Barleycorn AA, Nolan S, Christensen RD, Calhoun DA 2002 Effects of interleukin-8 on the developing human intestine. Cytokine 20:256-267

6. Maheshwari A, Lu W, Guida WC, Christensen RD, Calhoun DA2003 Interleukin-8 survives neonatal gastric digestion due to disulfide-bond related protein folding. Pediatr Res 53:387A

7. Stadnyk AW 1994 Cytokine production by epithelial cells. FASEB J 8:1041-1047

8. Nanthakumar NN, Fusunyan RD, Sanderson I, Walker WA 2000 Inflammation in the developing human intestine: a possible pathophysiologic contribution to necrotizing enterocolitis. Proc Natl Acad Sci U S A 97:6043-6048

9. Yang SK, Eckmann L, Panja A, Kagnoff MF 1997 Differential and regulated expression of $\mathrm{C}-\mathrm{X}-\mathrm{C}, \mathrm{C}-\mathrm{C}$, and $\mathrm{C}$-chemokines by human colon epithelial cells. Gastroenterology 113:1214-1223

10. Eckmann L, Jung HC, Schurer-Maly C, Panja A, Morzycka-Wroblewska E, Kagnoff MF 1993 Differential cytokine expression by human intestinal epithelial cell lines: regulated expression of interleukin 8. Gastroenterology 105:1689-1697 
11. Claud EC, Savidge T, Walker WA 2003 Modulation of human intestinal epithelial cell IL-8 secretion by human milk factors. Pediatr Res 53:419-425

12. Delie F, Rubas W 1997 A human colonic cell line sharing similarities with enterocytes as a model to examine oral absorption: advantages and limitations of the Caco-2 model. Crit Rev Ther Drug Carrier Syst 14:221-286

13. Sanderson IR, Ezzell RM, Kedinger M, Erlanger M, Xu ZX, Pringault E, LeonRobine S, Louvard D, Walker WA 1996 Human fetal enterocytes in vitro: modulation of the phenotype by extracellular matrix. Proc Natl Acad Sci U S A 93:7717-7722

14. Leers MP, Kolgen W, Bjorklund V, Bergman T, Tribbick G, Persson B, Bjorklund P, Ramaekers FC, Bjorklund B, Nap M, Jornvall H, Schutte B 1999 Immunocytochemical detection and mapping of a cytokeratin 18 neo-epitope exposed during early apoptosis. J Pathol 187:567-572

15. Bruewer M, Luegering A, Kucharzik T, Parkos CA, Madara JL, Hopkins AM, Nusrat A 2003 Proinflammatory cytokines disrupt epithelial barrier function by apoptosisindependent mechanisms. J Immunol 171:6164-6172

16. Gavrieli Y, Sherman Y, Ben-Sasson SA 1992 Identification of programmed cell death in situ via specific labeling of nuclear DNA fragmentation. J Cell Biol 119:493-501

17. Pole JR, McAllister TA 1975 Gastric aspirate analysis in the newborn. Acta Paediatr Scand 64:109-112

18. LoMonaco MB, Barber CM, Sinkin RA 1996 Differential cytokine mRNA expression by neonatal pulmonary cells. Pediatr Res 39:248-252

19. Huang HC, Yang MY, Huang CB, Yang KD 2000 Profiles of inflammatory cytokines in bronchoalveolar lavage fluid from premature infants with respiratory distress disease. J Microbiol Immunol Infect 33:19-24

20. Costa RH, Kalinichenko VV, Lim L 2001 Transcription factors in mouse lung development and function. Am J Physiol Lung Cell Mol Physiol 280:L823-L838

21. Montgomery RK, Mulberg AE, Grand RJ 1999 Development of the human gastrointestinal tract: twenty years of progress. Gastroenterology 116:702-731

22. Mukaida N, Okamoto S, Ishikawa Y, Matsushima K 1994 Molecular mechanism of interleukin-8 gene expression. J Leukoc Biol 56:554-558

23. Wilkinson DG, Bhatt S, Ryseck RP, Bravo R 1989 Tissue-specific expression of c-jun and junB during organogenesis in the mouse. Development 106:465-471

24. Villarete LH, Remick DG 1996 Transcriptional and post-transcriptional regulation of interleukin-8. Am J Pathol 149:1685-1693

25. Louvard D, Kedinger M, Hauri HP 1992 The differentiating intestinal epithelial cell: establishment and maintenance of functions through interactions between cellular structures. Annu Rev Cell Biol 8:157-195

26. Rindler MJ, Traber MG 1988 A specific sorting signal is not required for the polarized secretion of newly synthesized proteins from cultured intestinal epithelial cells. J Cell Biol 107:471-479

27. Appel D, Koch-Brandt C 1994 Sorting of a secretory protein (gp80) to the apical surface of Caco-2 cells. J Cell Sci 107:553-559

28. Bocker U, Schottelius A, Watson JM, Holt L, Licato LL, Brenner DA, Sartor RB Jobin C 2000 Cellular differentiation causes a selective down-regulation of interleukin (IL)-1beta-mediated NF-kappaB activation and IL-8 gene expression in intestinal epithelial cells. J Biol Chem 275:12207-12213

29. Maheshwari A, Alvarez AF, Christensen RD, Calhoun DA2003 Effect of feta enterocyte differentiation on interleukin-8 production. Pediatr Res 53:170A

30. Zachrisson K, Neopikhanov V, Wretlind B, Uribe A 2001 Mitogenic action of tumour necrosis factor-alpha and interleukin- 8 on explants of human duodenal mucosa. Cytokine 15:148-155

31. Wilson AJ, Byron K, Gibson PR 1999 Interleukin-8 stimulates the migration of human colonic epithelial cells in vitro. Clin Sci (Lond) 97:385-390

32. Alison MR, Sarraf CE 1994 The role of growth factors in gastrointestinal cell proliferation. Cell Biol Int 18:1-10
33. Liang H, Fesik SW 1997 Three-dimensional structures of proteins involved in programmed cell death. J Mol Biol 274:291-302

34. Schulze-Osthoff K, Krammer PH, Droge W 1994 Divergent signalling via APO-1/Fas and the TNF receptor, two homologous molecules involved in physiological cell death. EMBO J 13:4587-4596

35. Zachrisson K, Neopikhanov V, Samali A, Uribe A 2001 Interleukin-1, interleukin-8, tumour necrosis factor alpha and interferon gamma stimulate DNA synthesis but have no effect on apoptosis in small-intestinal cell lines. Eur J Gastroenterol Hepato 13:551-559

36. Osawa Y, Banno Y, Nagaki M, Brenner DA, Naiki T, Nozawa Y, Nakashima S, Moriwaki H 2001 TNF-alpha-induced sphingosine 1-phosphate inhibits apoptosis through a phosphatidylinositol 3-kinase/Akt pathway in human hepatocytes. J Immunol 167:173-180

37. Jobin C, Holt L, Bradham CA, Streetz K, Brenner DA, Sartor RB 1999 TNF receptor-associated factor-2 is involved in both IL-1 beta and TNF-alpha signaling cascades leading to NF-kappa B activation and IL-8 expression in human intestinal epithelial cells. J Immunol 162:4447-4454

38. Miller T, Beausang LA, Meneghini M, Lidgard G 1993 Death-induced changes to the nuclear matrix: the use of anti-nuclear matrix antibodies to study agents of apoptosis. Biotechniques 15:1042-1047

39. Baize S, Leroy EM, Georges-Courbot MC, Capron M, Lansoud-Soukate J, Debre P, Fisher-Hoch SP, McCormick JB, Georges AJ 1999 Defective humoral responses and extensive intravascular apoptosis are associated with fatal outcome in Ebola virusinfected patients. Nat Med 5:423-426

40. Hagg M, Biven K, Ueno T, Rydlander L, Bjorklund P, Wiman KG, Shoshan M, Linder S 2002 A novel high-through-put assay for screening of pro-apoptotic drugs. Invest New Drugs 20:253-259

41. Ruemmele FM, Schwartz S, Seidman EG, Dionne S, Levy E, Lentze MJ 2003 Butyrate induced Caco-2 cell apoptosis is mediated via the mitochondrial pathway. Gut 52:94-100

42. Zhang X, Cromwell JW, Kunjummen BD, Yee D, Garcia-Aguilar J 2003 The alpha2 and alpha3 integrins are required for morphologic differentiation of an intestinal epithelial cell line. Surgery 133:429-437

43. Doi TS, Marino MW, Takahashi T, Yoshida T, Sakakura T, Old LJ, Obata Y 1999 Absence of tumor necrosis factor rescues RelA-deficient mice from embryonic lethality. Proc Natl Acad Sci U S A 96:2994-2999

44. Vachon PH, Cardin E, Harnois C, Reed JC, Vezina A 2000 Early establishment of epithelial apoptosis in the developing human small intestine. Int J Dev Biol 44:891898

45. Osawa Y, Nagaki M, Banno Y, Brenner DA, Asano T, Nozawa Y, Moriwaki H, Nakashima S 2002 Tumor necrosis factor alpha-induced interleukin-8 production via NF-kappaB and phosphatidylinositol 3-kinase/Akt pathways inhibits cell apoptosis in human hepatocytes. Infect Immun 70:6294-6301

46. Glynn PC, Henney E, Hall IP 2002 The selective CXCR2 antagonist SB272844 blocks interleukin-8 and growth-related oncogene-alpha-mediated inhibition of spontaneous neutrophil apoptosis. Pulm Pharmacol Ther 15:103-110

47. Saas P, Walker PR, Quiquerez AL, Chalmers DE, Arrighi JF, Lienard A, Boucraut J, Dietrich PY 2002 A self-defence mechanism of astrocytes against Fas-mediated death involving interleukin-8 and CXCR2. Neuroreport 13:1921-1924

48. Belperio JA, Keane MP, Arenberg DA, Addison CL, Ehlert JE, Burdick MD, Strieter RM 2000 CXC chemokines in angiogenesis. J Leukoc Biol 68:1-8

49. Dunican A, Grutkoski P, Leuenroth S, Ayala A, Simms HH 2000 Neutrophils regulate their own apoptosis via preservation of CXC receptors. J Surg Res 90:32-38

50. Maheshwari A, Christensen RD, Calhoun DA 2003 ELR + CXC chemokines in human milk. Cytokine 24:91-102 